Copy of paper: Burgess, P.J., Reinhard, B.R. \& Pasturel, P. (2006). Compatible measurements of volumetric soil water content using a neutron probe and Diviner 2000 after field calibration. Soil Use and Management, December 2006, 22: 401-404.

\title{
Compatible measurements of volumetric soil water content using a neutron probe and Diviner 2000 after field calibration
}

\author{
P.J. Burgess ${ }^{1 *}$, B.R. Reinhard ${ }^{12}$ \& P. Pasturel ${ }^{1}$ \\ ${ }^{1}$ Cranfield University, Cranfield, Bedfordshire, MK43 0AL, UK. \\ ${ }^{2}$ Büro für Ökologie und Landschaft GmbH, Litzibuch, CH-8966 Oberwil-Lieli, Switzerland \\ *Corresponding author. E-mail: P.Burgess@cranfield.ac.uk
}

Key words: Capacitance sensor, shrinking-swelling clay, soil texture, neutron probe

\begin{abstract}
Field calibrations for a neutron probe and a capacitance sensor (Diviner 2000) for measuring the soil water content of a shrinking-swelling clay soil were substantially different from commonly-used default values. Using our field calibrations, the instruments estimated similar changes in the cumulative water content of a soil profile (0 to $1 \mathrm{~m}$ depth) over one growing season.
\end{abstract}

\section{INTRODUCTION}

Irrigation scheduling and environmental monitoring require accurate, portable and costeffective methods for measuring volumetric soil water content $\left(\theta_{\mathrm{v}}\right)$. Since the 1950s, soil water content has been measured using neutron scattering (Gardner and Kirkham, 1952) and it is common practice in the UK to use the default calibration equations for clay, silt and sand soils described by Bell (1987). Soil water content can also be measured using capacitance sensors calibrated for soil texture (Groves and Rose, 2004; Mwale et al., 2005).

Between April and October 2003 the soil water content in a shrinking-swelling clay soil was measured using a Wallingford-type neutron probe (Bell, 1987) and a Diviner 2000 capacitance sensor (Sentek Pty, Stepney, South Australia). Using Bell's (1987) default calibration for a clay soil and a site-specific calibration for the capacitance sensor, the two techniques showed substantial divergence in calculated soil water content (Pasturel, 2004). The objective of the research, described here, was to determine if recalibrations of the neutron probe and capacitance sensor, against gravimetrically-determined volumetric water contents, could remove the divergence. 


\section{METHOD}

All of the soil water content measurements were taken in a clay soil within an experimental site at Silsoe, Bedfordshire, UK (lat. $52^{\circ} 0^{\prime} \mathrm{N}$; long. $0^{\circ} 25^{\prime} \mathrm{W}$ ) described by Burgess et al. (2004). The vegetation comprised widely-spaced $(10 \mathrm{~m}$ x $6.4 \mathrm{~m}) 11$ to 13-year-old poplar trees (Populus spp) with an understorey of grass, bare earth or field beans (Vicia faba). The soil, classified as belonging to the Holdenby soil series, comprises 55\% clay ( $<2 \mu \mathrm{m}), 26 \%$ silt (2 to $63 \mu \mathrm{m})$, and $19 \%$ sand $(0.063$ to $2 \mathrm{~mm})$, with some stones $(<60 \mathrm{~mm})$ to $0.80 \mathrm{~m}$ depth, and it swells and shrinks in response to wetting and drying.

For the calibration four $1 \mathrm{~m}$ long neutron probe aluminium access-tubes (external diameter: $44 \mathrm{~mm}$ ) each spaced $0.5 \mathrm{~m}$ from a corresponding $1.5 \mathrm{~m}$ long PVC Diviner access tube (diameter: $56 \mathrm{~mm}$ ) were installed along an $8 \mathrm{~m}$ transect. During installation, a clay and water mixture was added around the Diviner access-tubes to minimise air gaps. During the next two months, neutron probe and Diviner measurements were taken at depths of 0.25 , $0.40,0.60$ and $0.80 \mathrm{~m}$ below the soil surface within each of the four pairs of access-tubes. The neutron probe measurement comprised a count ratio $(C R)$ determined by dividing the mean of five 16 seconds field measurements at each depth $\left(R_{\mathrm{s}}\right)$ by a 64 second standard count $\left(R_{w}\right)$ inside a drum of water. The Diviner was used to determine a scaled frequency $(S F)$ calculated from the mean value of three frequency counts at each depth $\left(F_{s}\right)$ and inside 200 litre containers containing either air $\left(F_{a}\right)$ or water $\left(F_{w}\right)$ at $22^{\circ} \mathrm{C}$ (equation 1 ):

$$
S F=\frac{F_{a}-F_{s}}{F_{a}-F_{w}}
$$

Immediately after these measurements, standard cutting rings (54 mm diameter and $20 \mathrm{~mm}$ deep) were used to remove three undisturbed soil samples centred at depths of $0.25,0.40$, 0.60 and $0.80 \mathrm{~m}$ next to each access tube. The mean bulk density and water content $( \pm 0.01$ g) were determined by weighing the samples, placing in a drying oven at $105^{\circ} \mathrm{C}$ for $72 \mathrm{~h}$, and reweighing. Analysis of variance was used to determine if mean bulk density varied with soil depth, and new calibration equations were established from regressions of volumetric water content against instrument reading (count ratio or scaled frequency) using Genstat version 8.0 (Lawes Agricultural Trust).

The mean soil-profile (0 to $1 \mathrm{~m}$ depth) water contents (units: $\mathrm{cm}^{3} \mathrm{~cm}^{-3}$ ), measured in the experimental site between April and October 2003 (Pasturel, 2004), were then recalculated using the new calibrations. With the neutron probe, the mean water content between a depth of 0 and $0.25 \mathrm{~m}$ was assumed to be the same as that at the shallowest reading i.e. a depth of $0.25 \mathrm{~m}$. With the capacitance sensor, soil water measurements had been taken in $0.10 \mathrm{~m}$ increments between depths of 0.10 and $1.00 \mathrm{~m}$.

\section{RESULTS AND DISCUSSION}

The analysis of variance indicated that the mean dry bulk density $\left(1.30 \pm 0.015 \mathrm{~g} \mathrm{~cm}^{-3} ; \mathrm{n}=\right.$ 32) was similar between the four depths and four pairs of access-tubes. There was a positive linear relationship between volumetric water content $\left(\theta_{v}\right)$ and the neutron probe count ratio $(C R)$ (Figure 1a; equation 2) which was not significantly affected by depth $(P=0.05)$ :

$$
\theta_{\mathrm{v}}=0.754( \pm 0.076) C R+0.057( \pm 0.039) \quad\left(R^{2}=0.87 ; \mathrm{n}=16\right)
$$

The slope of the calibration suggests a $21 \%$ reduction in calculated water use compared to Bell's (1987) default calibration for clay (Table 1a). Although neutron probes have been widely used for soil water monitoring in temperate clay soils and are often considered to be a standard for other methods, these results reinforce the need to develop site-specific calibrations (Fares et al. 2003). Although few neutron probe calibrations for temperate clay soils are cited in the literature, Jarvis and Leeds-Harrison (1987) report a similar calibration for a clay soil at a depth of $0.30 \mathrm{~m}$ at the same site (Table $1 \mathrm{a}$ ). 
a) Neutron probe

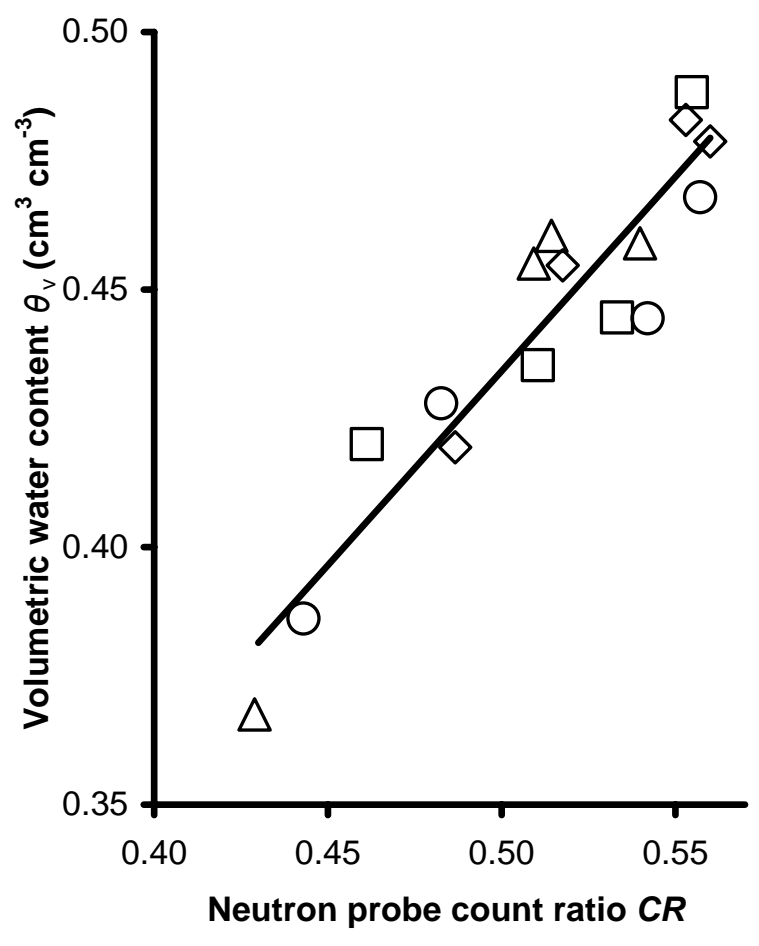

b) Diviner 2000

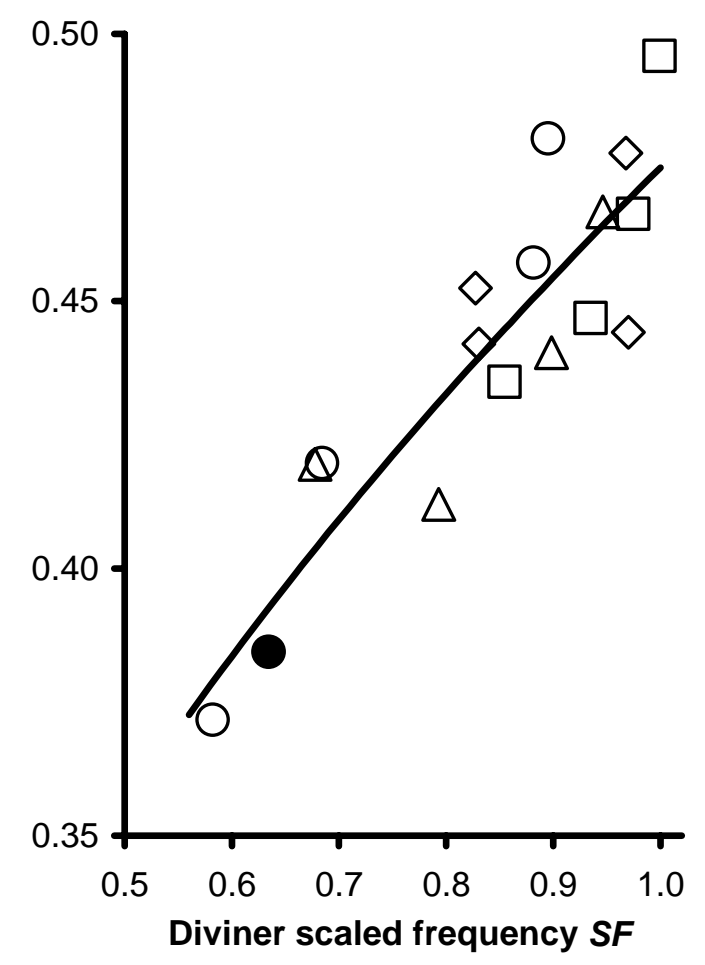

Legend: $\bullet: 20 \mathrm{~cm}, \bigcirc: 25 \mathrm{~cm}, \triangle: 40 \mathrm{~cm}, \diamond: 60 \mathrm{~cm}, \square: 80 \mathrm{~cm}$ depth

Figure 1 Relation between the gravimetrically-determined volumetric water content $\left(\theta_{v}\right)$ of the clay soil at up to five depths (20 to $80 \mathrm{~cm}$ ) and the associated a) neutron probe count ratio $(C R)$ and b) the Diviner 2000 scaled frequency readings $(S F)$. The best fit regressions (equations 2 and 3 ) are shown as solid black lines.

Table 1 Calibration equations and coefficients of determination $\left(R^{2}\right)$ used to calculate volumetric water content $\left(\theta_{\mathrm{v}} ; \mathrm{cm}^{3} \mathrm{~cm}^{-3}\right)$ from a) the count ratio $(C R)$ measured with a Wallingford neutron probe on clay soils in the UK, and b) the scaled frequency $(S F)$ measured with a Diviner 2000 on soils with a high clay content.

\begin{tabular}{lllll}
\hline $\begin{array}{l}\text { Instrument and } \\
\text { soil texture }\end{array}$ & Calibration equation & $R^{2}$ & $\begin{array}{l}\text { Bulk density } \\
\left(\mathrm{g} \mathrm{cm}^{-3}\right)\end{array}$ & Reference \\
\hline $\begin{array}{lllll}\text { a) Neutron probe } \\
\text { Clay (20 to 80 cm) }\end{array}$ & $\theta_{v}=0.754 C R+0.057$ & 0.87 & 1.30 & Current study \\
Clay (30 cm) & $\theta_{v}=0.769 C R+0.038$ & 0.87 & 1.30 & $\begin{array}{l}\text { Jarvis and Leeds-Harrison (1987) } \\
\text { Clay and peat }\end{array}$ \\
$\theta_{v}=0.958 C R-0.012$ & na & na & Bell (1987) \\
\hline b) Diviner 2000 & & & & \\
Clay (field) & $\theta_{v}=0.475 S F^{0.418}+0$ & 0.81 & 1.30 & Current study \\
& $\theta_{v}=0.228 S F+0.250$ & 0.78 & 1.30 & Current study \\
Clay (laboratory) & $\theta_{v}=0.514 S F^{3.371}+0$ & 0.93 & 1.09 & Groves and Rose (2004) \\
Silty clay (field) & $\theta_{v}=0.465 S F-0.139$ & 0.80 & 1.29 & Hidalgo et al. (2003) \\
\hline na = not available. & & & &
\end{tabular}


As recommended by Sentek Pty Ltd (2003), a power law relationship was first used to calibrate the scaled frequency of the Diviner and the soil water content (Figure 1b; equation 3):

$$
\theta_{\mathrm{v}}=0.475( \pm 0.006) S F^{0.4187( \pm 0.0523)} \quad\left(R^{2}=0.80 ; \mathrm{n}=17\right)
$$

A linear model of the form: $\theta_{\mathrm{v}}=0.228( \pm 0.030) S F+0.250( \pm 0.026)$ had an equivalent but slightly lower coefficient of determination $\left(R^{2}=0.78\right)$. In the field, the predicted change in soil water content per change in the scaled frequency was substantially less than that determined for clay in a laboratory study by Groves \& Rose (2004) (Table 1b). Capacitance probes, such as the Diviner, measure a relatively small soil volume (approximately $0.10 \mathrm{~m}$ from the access tube) and are sensitive to macro-pores and cracks (Paltineanu \& Starr, 1993). The lack of correspondence between our calibration and other soils with a high clay content (e.g. Hidalgo et al. 2003) may be a result of differences in the chemical composition of the soil, the range of the soil water content, the electroconductivity of the soil solution, temperature changes (Paltineanu \& Starr, 1993), or the presence of stones and possible changes in soil texture with depth (Mwale et al. 2005). The differences in calibration equations again highlights the importance of site-specific calibrations for accurate measurement of soil water content.

The new calibrations were used to re-calculate the soil water contents ( 0 to $1 \mathrm{~m}$ depth) of the clay soil between April and October 2003 using the raw data collected by Pasturel (2004). With these calibrations, the two instruments gave similar $(P=0.05)$ absolute values for soil water content at the start and the end of the season (Figure 2 ) suggesting that the calibrations were correct. The two methods also predicted a similar $(P=0.05)$ net change in the water content (153-170 mm) of the top $1 \mathrm{~m}$ of soil between 29 April and 15 October (Figure 2). The main difference between the two methods was that the Diviner measurements showed a sudden rise in soil water content on 30 July. Following $20 \mathrm{~mm}$ of rainfall between 24 and 30 July, this may be due to the greater sensitivity of the Diviner 2000 readings to water preferentially running along the outside of the access tube and into the soil. In addition the shallowest reading with the capacitance sensor was at a depth of $0.10 \mathrm{~m}$ compared to $0.25 \mathrm{~m}$ for the neutron probe.

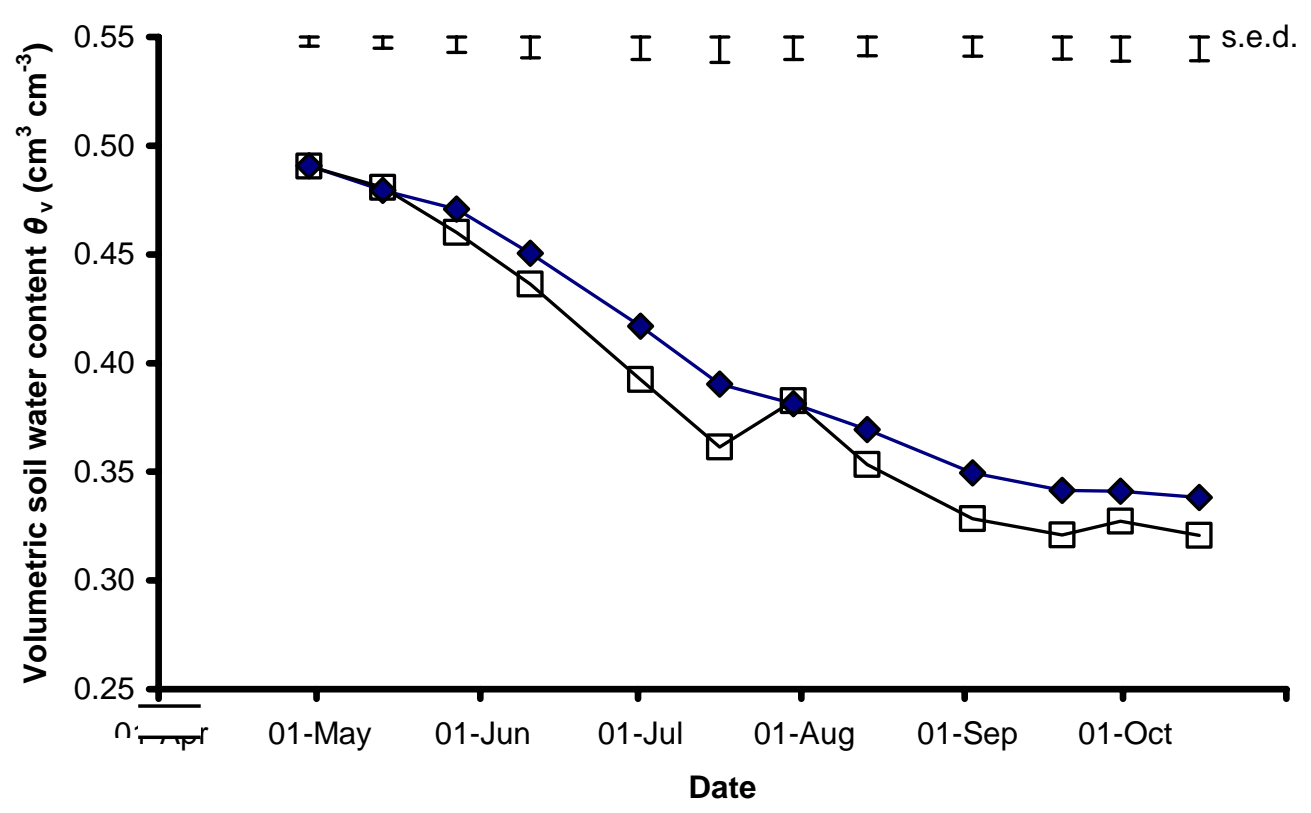

Figure 2 Mean water content for the soil profile (0 to $1 \mathrm{~m}$ depth) as measured with the neutron probe $\checkmark$ and the Diviner $2000 \square$ between 29 April and 15 October 2003 using the field-determined calibrations equations 2 and 3. Error bars show the standard error of the difference between the neutron probe and Diviner readings $(n=11)$. 


\section{CONCLUSION}

For a shrinking-swelling clay, the field calibration equations for a neutron probe and Diviner 2000 capacitance sensor were substantially different from default or laboratory-determined equations obtained by previous authors. By using the field, rather than the default, calibrations the two instruments gave similar estimates of the change in the water content of a soil profile (0 to $1 \mathrm{~m}$ depth) over a growing season.

\section{ACKNOWLEDGEMENT}

The field measurements from April to October 2003 were undertaken when Pascal Pasturel was funded by European Union project No. QLK5-CT-2001-00560.

\section{REFERENCES}

Bell JP 1987. Neutron Probe Practice. Institute of Hydrology. Report 19.

Burgess PJ Incoll LD Corry DT Beaton A \& Hart BJ 2004. Poplar growth and crop yields within a silvoarable agroforestry system at three lowland sites in England. Agroforestry Systems 63, 157-169.

Fares A Buss P Dalton M El-Kadi AI \& Parsons LR 2004. Dual field calibration of capacitance and neutron soil water sensors in a shrinking-swelling clay soil. Vadose Zone Journal 3, 1390-1399.

Gardner W \& Kirkham D 1952. Determination of soil moisture by neutron scattering. Soil Science 73, 391-401.

Groves SJ \& Rose SC 2004. Calibration equations for Diviner 2000 capacitance measurements of volumetric soil water content of six soils. Soil Use and Management 20, 96-97.

Hidalgo J Pastor M \& Hidalgo JC 2003. Evaluacion de una sonda FDR para la estimacióde la evolución del contenido de agua en el suelo y para el control de riegos en olivar. In: Estudios de la Zona No Saturada del Suelo Vol. VI, (eds J Álvarez-Benedí \& P Marinero), Instituto Tecnológico Agrario de Castilla y León, Valladolid Spain, pp 171-176.

Jarvis NJ \& Leeds-Harrison PB 1987. Some problems associated with the neutron probe in swelling/shrinking clay soil. Journal of Soil Science 38, 149-156.

Mwale SS, Azam-Ali SN \& Sparkes DL 2005. Can the PR1 capacitance probe replace the neutron probe for routine soil-water measurement? Soil Use and Management 21, 340-347

Paltineanu IC \& Starr JL 1997. Real-time soil water dynamics using multisensor capacitance probes: laboratory calibration. Soil Science Society of America Journal 61, 1576-1585.

Pasturel P 2004. Light and water use in a poplar silvoarable system. MSc by Research Thesis, Cranfield University, Silsoe, UK

Sentek Pty Ltd 2003. Sentek Diviner 2000 User Guide Version 1.2. Australia: Sentek Pty Ltd, Stepney, South Australia. 